\title{
Analysis of Level Practice Satisfaction on Basic Chemical Laboratory Performance Faculty of MIPA Jenderal Soedirman University
}

\author{
Diah Ratna Anggraeni*, Nailatul Azizah \\ Mathematics Education Department, Faculty of Math and Science, Jenderal Soedirman University, \\ J1. Dr. Soeparno Karangwangkal Purwokerto 53123, Indonesia. Tel. (0281) 638793, Fax. (0281) 638793 \\ Email*:diahratnaanggraeni@gmail.com
}

\begin{abstract}
Education is an important aspect of life. In the context of providing education, it is necessary to have adequate human resources and supporting facilities. The level of performance of officers from each facility must also be considered in order to create the desired learning conditions. To find out the level of performance of the services provided in accordance with what is desired or not is to conduct a survey of facility users regarding all aspects of the facility. Therefore, the authors use the Partial Least Square method to analyze the influence of human resource factors and facilities and infrastructure on the satisfaction of the students at the Laboratory of the Faculty of Mathematics and Natural Sciences, Jenderal Soedirman University. From the results of the Partial Least Square analysis, it was concluded that human resources and facilities and infrastructure had a significant influence on the satisfaction of the practitioners in the Basic Chemistry Laboratory of the Faculty of Mathematics and Natural Sciences, Jenderal Soedirman University. This shows that there must be an increase in the quality of the performance of natural resources and facilities and infrastructure in order to create the desired learning conditions.
\end{abstract}

Keywords: Laboratory, partial least square (PLS), satisfaction

\section{INTRODUCTION}

Education is one of the important aspects of life, because human resource though the educational process the mindset of individuals or groups will be formed which will ultimately affect the quality of life of individuals or groups. In the context of providing education, it is necessary to have adequate human resources and supporting facilities and infrastructure. The level of performance of officers from each facility must also be considered in order to create the desired learning conditions.

To find out the level of performance of services provided in accordance with what is desired or not is to conduct a survey of facility users regarding all aspects of the facility. Aspects of the research can be in the form of staff performance, availability of supporting facilities and infrastructure, and so forth.

For these reasons, a satisfaction analysis needs to be conducted regularly by the facility manager, so that the facility can find out what needs to be improved or further improved to maintain or even improve the quality of the facility concerned.

In this study variant-based Structural Equation Modeling (SEM) methods, or better known as Partial Least Squares (PLS), are used to measure the satisfaction index.

Based on its statistical assumptions, PLS is classified as a non-parametric type. Therefore, in PLS modeling no data are needed with a normal distribution. In terms of construction, PLS can accommodate both formative and reflective. Because PLS is based on variants, the number of samples used does not need to be large. The sample used can range between 30-100.

Therefore, the authors are interested in analyzing the variables in the study using the Partial Least Square (PLS) method. Thus, it can be analyzed the relationship between variables that affect the satisfaction index of the services provided.

\section{MATERIALS AND METHODS}

\section{Study area}

The research is carried out in the Laboratory of the Faculty of Mathematics and Sciences, Jenderal Soedirman University which is located on the campus of Jenderal Soedirman University, Karangwangkal St., Dr. Soeparno, Karangwangkal, Purwokerto.

\section{Procedures}

The steps in the Partial Least Square (PLS) analysis will be explained as follows:

1. Designing structural models (inner models).

Designing a structural model (inner model), which is designing relationships between latent variables in PLS based on the research hypothesis. And designing a Measurement Model (outer model). Designing a measurement model (outer model), which is designing the relationship of latent variables with 
indicators. In PLS the design of the outer model is very important, reflexive or formative.

2. Path chart construction.

Constructing a path diagram based on the design of the outer model and inner model. The results of the design of the outer model and the inner model are expressed in the form of a path diagram to be more easily understood.

3. Convert path chart to equation system

a) Outer model

Outer model, which is the specification of the relationship between latent constructs and indicators. The outer model, also called the outer relation or measurement model, defines construct characteristics with their manifest variables. The outer model equation of the reflexive indicator model is:

$$
\begin{aligned}
& x=\Lambda_{x} \xi+\delta_{x} \\
& y=\Lambda_{y} \eta+\varepsilon_{y}
\end{aligned}
$$

Where $\xi$ and $\eta$ are indicators relating to exogenous latent ( $\xi$ ) and endogenous $(\eta), \Lambda_{x}$ and $\Lambda_{y}$ are the coefficient matrices that connect latent variables with their indicators, $\delta_{x}$ and $\varepsilon_{y}$ are residual measurement errors The equations for formative indicator models can be written as follows:

$$
\begin{aligned}
& \xi=\Pi_{\xi} x+\delta_{\xi} \\
& \eta=\Pi_{\eta} y+\delta_{\eta}
\end{aligned}
$$

Where $\xi$ and $\eta$ are indicators related to latent exogenous $(\xi)$ and endogenous $(\eta), \Pi_{\xi}$ and $\Pi_{\eta \eta}$ are the coefficient matrices of latent variables to the indicator, $\delta_{\xi}$ and $\delta_{n}$ are the residuals of the regression.

\section{b) Inner model}

Inner model, which is the specification of the relationship between latent variables (structural model). The inner equation of the model can be written as follows:

$$
\eta=\beta_{n}+\Gamma \xi+\zeta
$$

Where $\eta$ is the endogenous latent construct, $\xi$ is the exogenous latent construct, $\beta$ and $\Gamma$ is a matrix of endogenous and exogenous coefficients and variables, $\zeta$ is an error vector in the structural equation.

4. Evaluate the SEM-PLS model

Evaluation of the measurement model is carried out as follows:

\section{a) Outer model}

The measurement model (outer model) is evaluated by looking at:

- Convergent validity.

- Discriminant validity.

- Composite reliability.

- Cronbach alpha.

\section{b) Inner model}

Structural models (inner models) is evaluated by looking at the presentase variance explained by looking $R^{2}$ for the dependent latent constructs using size Stone-Geisser $Q^{2}$ test and also see the coefficient of structural lines.

5. Conduct hypothesis testing (bootstrapping resampling).

Hypothesis testing $(\beta, \gamma$ and $\lambda)$ is done by bootstrapping resampling method. The test statistic used is the $\mathrm{t}$ statistic or $\mathrm{t}$ test with the statistical hypothesis that has been explained in the previous section.

6. Draw a conclusion

After the hypothesis is obtained, it can be concluded whether there is an influence between the latent variable and the research manifest variable.

\section{Data analysis}

The data used is the result of survey data on the level of student satisfaction in Basic Chemistry laboratory services at the Faculty of Mathematics and Natural Sciences. The number of respondents obtained from this study were 37 respondents. The target respondents in this study were non-Faculty of Mathematics and Natural Sciences UNSOED students.

The variables used in this study are as many as two independent variables, namely the Human Resource variable $\left(X_{1}\right)$ and the Means and Infrastructure variable ( $X_{2}$ ) and one dependent variable, the Satisfaction variable (Y). Each variable has four indicators including:

- For the Human Resource variable $\left(X_{1}\right)$

Indicator $X_{1.1}$ is shown by question 2 on the questionnaire. This is because P2 is questioning the level of human resource capability in terms of rules and practicum prerequisites.

Indicator $X_{12}$ is shown by question 3 on the questionnaire. This is because P3 questions the level of human resource capability in terms of the material applied in the practicum.

Indicator $X_{13}$ is shown by question 9 in the questionnaire. This is because P9 questions the level of human resource capability in terms of responsiveness to help practitioners in the field of administration.

Indicator $X_{1.4}$ is shown by question 10 on the questionnaire. This is because P10 questions the level of human resource capability in terms of responsiveness to help practitioners who have difficulty understanding material.

- For Facilities and Infrastructure variables $\left({ }_{2}\right)$ Indicator $X_{2.1}$ is shown by question 6 in the questionnaire. This is because P6 questioned the availability of SOPs or loan books to facilitate the borrowing of laboratory space. 
Indicator $X_{22}$ is shown by question 8 in the questionnaire. This is because $\mathrm{P} 8$ questions the condition of the practicum equipment.

Indicator $X_{2.3}$ is shown by question 11 in the questionnaire. This is because P11 questions the availability of practicum modules.

Indicator $X_{2,4}$ is shown by question 12 in the questionnaire. This is because P12 questions the availability and condition of other facilities such as air conditioning, connectivity, luggage belonging to practice, chairs + tables, and so forth.

- For the Satisfaction variable $(Y)$

The indicator $Y_{1}$ is shown by question 1 on the questionnaire. This is because P1 questions the practical satisfaction of the service of administrative staff or practicum assistants.

The indicator $Y_{2}$ is shown by question 4 on the questionnaire. This is because P4 questions the satisfaction of the practitioners with the guidance of practicum assistants.

Indicator $Y_{3}$ is shown by question 5 on the questionnaire. This is because P5 questions the satisfaction of the practitioners with the help of practicum assistants in understanding the practical material.

Indicator $Y_{4}$ is shown by question 7 on the questionnaire. This is because P7 questions the practical satisfaction of the laboratory space.

\section{RESULTS AND DISCUSSION}

Designing structural model and measurement model (inner model and outer model)

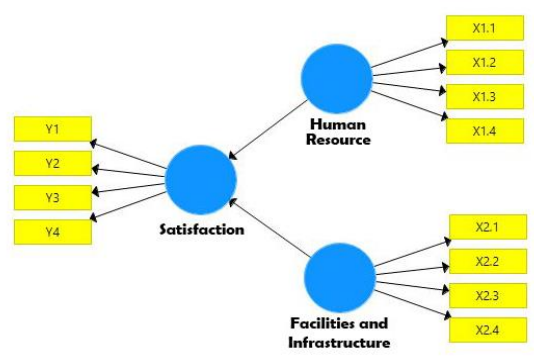

Figure 1. Structural Model: Relationship beetwen Satisfaction variable with Human Resource and Facilities and Infrastructure variables

\section{Path chart construction}

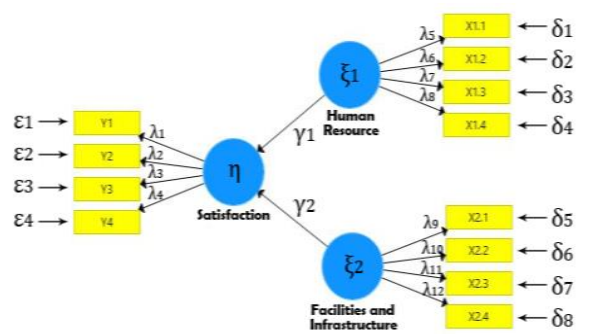

Figure 2. Conceptual framework for research based on Structural Model and Measurement Model

\section{Convert path chart to equation system}

- Outer model

1. For exogenous latent variables 1 (reflexive)

$X_{1.1}=\lambda X \xi_{1}+\delta_{1}$

$X_{1.2}=\lambda X \xi_{1}+\delta_{2}$

$X_{1.3}=\lambda X \xi_{1}+\delta_{3}$

$X_{1.4}=\lambda X \xi_{1}+\delta_{4}$

2. For exogenous latent variables 2 (reflexive)

$X_{2,1}=\lambda X \xi_{2}+\delta_{5}$

$X_{2,2}=\lambda X \xi_{2}+\delta_{6}$

$X_{2,3}=\lambda X \xi_{2}+\delta_{7}$

$X_{2,4}=\lambda X \xi_{2}+\delta_{g}$

3. For endogenous latent variables (reflexive)

$Y_{1}=\lambda_{Y 1} \eta+\varepsilon_{1}$

$Y_{2}=\lambda_{Y 2} \eta+\varepsilon_{2}$

$Y_{3}=\lambda_{Y 3} \eta+\varepsilon_{3}$

- Inner model

$\eta=\gamma_{1} \xi_{1}+\gamma_{2} \xi_{2}+\zeta$

Satisfaction $=\gamma_{1}$ Human Resource $+\gamma_{2}$ Facilities and Infrastructure $+\zeta$

\section{Evaluation of the SEM-PLS model}

Evaluation of the model in PLS include two stage, that is evaluation of the measurement model (outer model) and evaluation of the structural model (inner model).

\section{- Outer Model}

\section{Convergent validity}

Evaluation of convergent validity is used to measure the correlation between each measurement item (indicator) with its construct. Correlation value can be said to be valid if it has a value greater than 0,7 . The following is the output of the measurement model with SmartPLS:

Tabel 1. Outer Loading Model.

\begin{tabular}{cccc}
\hline & Satisfaction & $\begin{array}{c}\text { Human } \\
\text { Resource }\end{array}$ & $\begin{array}{c}\text { Facilities and } \\
\text { Infrastructure }\end{array}$ \\
\hline $\boldsymbol{Y}_{1}$ & 0,358 & & \\
$\boldsymbol{Y}_{2}$ & 0,723 & & \\
$\boldsymbol{Y}_{3}$ & 0,548 & & \\
$\boldsymbol{Y}_{4}$ & 0,633 & & \\
$\boldsymbol{X}_{1.1}$ & & 0,672 & \\
$\boldsymbol{X}_{1.2}$ & & 0,782 & \\
$\boldsymbol{X}_{13}$ & & 0,819 & \\
$\boldsymbol{X}_{14}$ & & 0,708 & \\
$\boldsymbol{X}_{2.1}$ & & & 0,722 \\
$\boldsymbol{X}_{2.2}$ & & & 0,696 \\
$\boldsymbol{X}_{2.3}$ & & & 0,687 \\
$\boldsymbol{X}_{2.4}$ & & & 0,840 \\
\hline
\end{tabular}

- Indicator $Y_{1}$ has a relationship of 0,358 with the satisfaction variable.

- Indicator $Y_{2}$ has a relationship of 0,723 with the satisfaction variable. 
- Indicator $Y_{3}$ has a relationship of 0,548 with the satisfaction variable.

- Indicator $Y_{4}$ has a relationship of 0,633 with the satisfaction variable.

- Indicator $X_{1,1}$ has a relationship of 0,672 with the human resource variable.

- Indicator $X_{1.2}$ has a relationship of 0,782 with the human resource variable.

- Indicator $X_{1.3}$ has a relationship of 0,819 with the human resource variable.

- Indicator $X_{1,4}$ has a relationship of 0,708 with the human resource variable.

- Indicator $X_{2,1}$ has a relationship of 0,722 with the variable Facilities and Infrastructure.

- Indicator $X_{2.2}$ has a relationship of 0,696 with the variable Facilities and Infrastructure.

- Indicator $X_{2.3}$ has a relationship of 0,687 with the variable Facilities and Infrastructure.

- Indicator $X_{2,4}$ has a relationship of 0,840 with the variable Facilities and Infrastructure. that:

Based on above explanation, it can be interpreted

a. Satisfaction has four indicators namely $Y_{1}, Y_{2}, Y_{a}$ and

$Y_{4}$. Each of four indicators has a loading factor value:

$Y_{1}$ with loading factor of 0,358 ; $Y_{2}$ with loading factor of 0,$723 ; Y_{3}$ with loading factor 0,548 ; and $Y_{4}$ with loading factor of 0,633 . In accordance with the tolerance limit of the convergent validity value criteria is $>0,6, Y_{1}$ and $Y_{a}$ are not include in the convergent validity criterion because they have a value less than 0,6 .

b. Human Resources has four indicators namely $X_{1.1}$, $X_{1.2}, X_{1.3}$, and $X_{1.4}$. Each of the four indicators has a loading factor value: $X_{1.1}$ with loading factor of 0,$672 ; X_{1.2}$ with loading factor of 0,$782 ; X_{1.3}$ with loading factor of 0,819 ; and $X_{1,4}$ with loading factor of 0,708 . In accordance with the tolerance limit of the convergent validity value criteria $>0,6$, the four indicators of the human resource variable are included in the convergent validity criterion because they have a value $>0,6$.

c. Facilities and Infrastructure have four indicators namely $X_{2,1}, X_{2.2}, X_{2.3}$, and $X_{2.4}$. each of the four indicators has a loading factor value: $X_{2,1}$ with loading factor of 0,$722 ; X_{2.2}$ with loading factor of 0,$696 ; X_{2,3}$ with loading factor of 0,687 , and $X_{2,4}$ with loading factor of 0,840 . In accordance with the tolerance limit of the convergent validity value criteria $>0,6$, the four indicators of the Facilities and Infrastructure variables are included in the convergent validity criterion because they have a value $>0,6$.
From the above interpretation, it can be concluded that the indicators that fall into the convergent validity criteria are as follows:

Table 2. Measurement of Convergent Validity Criteria.

\begin{tabular}{ccccc}
\hline No. & Indicator & $\begin{array}{c}\text { Outer } \\
\text { Loading }\end{array}$ & $\begin{array}{c}\text { Convergent } \\
\text { Validity } \\
\text { Criteria }\end{array}$ & Anotation \\
\hline 1. & $Y_{1}$ & 0,358 & & Invalid \\
2. & $Y_{2}$ & 0,723 & & Valid \\
3. & $Y_{3}$ & 0,548 & & Invalid \\
4. & $Y_{4}$ & 0,633 & & Valid \\
5. & $X_{1,1}$ & 0,672 & & Valid \\
6. & $X_{1,2}$ & 0,782 & $>0,6$ & Valid \\
7. & $X_{1,3}$ & 0,819 & & Valid \\
8. & $X_{1.4}$ & 0,708 & & Valid \\
9. & $X_{2,1}$ & 0,722 & & Valid \\
10. & $X_{2,2}$ & 0,696 & & Valid \\
11. & $X_{2,3}$ & 0,687 & & Valid \\
12. & $X_{2,4}$ & 0,840 & & Valid \\
\hline
\end{tabular}

Because indicators $Y_{1}$ and $Y_{3}$ do not meet the criteria (invalid), they are excluded from the model. The outer loading after the indicators $\mathrm{Y} 1$ and $\mathrm{Y} 3$ are released are as follows:

Table 3. Outer Loading of the Final Model.

\begin{tabular}{cccc}
\hline & Satisfaction & $\begin{array}{c}\text { Human } \\
\text { Resource }\end{array}$ & $\begin{array}{c}\text { Facilities and } \\
\text { Infrastructure }\end{array}$ \\
\hline$Y_{2}$ & 0,709 & & \\
$Y_{4}$ & 0,773 & & \\
$X_{1,1}$ & & 0,736 & \\
$X_{1,2}$ & & 0,722 & \\
$X_{1,3}$ & & 0,771 & \\
$X_{1,4}$ & & 0,763 & \\
$X_{2,1}$ & & & 0,728 \\
$X_{2,2}$ & & & 0,671 \\
$X_{2,3}$ & & & 0,685 \\
$X_{2,4}$ & & & 0,854 \\
\hline
\end{tabular}

2. Discriminant validity

On the evaluation of discriminant validity, the value of discriminant validity than the value of Average Variance Extracted (AVE). According to (Tasha Hoover, 2005 and Sofyan Yamin, 2005) highly recommended if the AVE value is greater than 0.5 . Following are the results of AVE measurement measurements for each variable: 
Table 4. Measurement Criteria AVE.

\begin{tabular}{ll}
\hline Variable & AVE \\
\hline Satisfaction & 0,550 \\
Human Resource & 0,560 \\
Facilities and infrastructure & 0,544 \\
\hline
\end{tabular}

From the measurement results above, it can be seen that the AVE value of the all three variables is greater than 0,5 . This indicate that all three variables are valid or can be used as a measurement tool. From the results of testing validity with convergent validity and discriminant validity obtain valid indicators to measure latent variables. The indicators include the following:

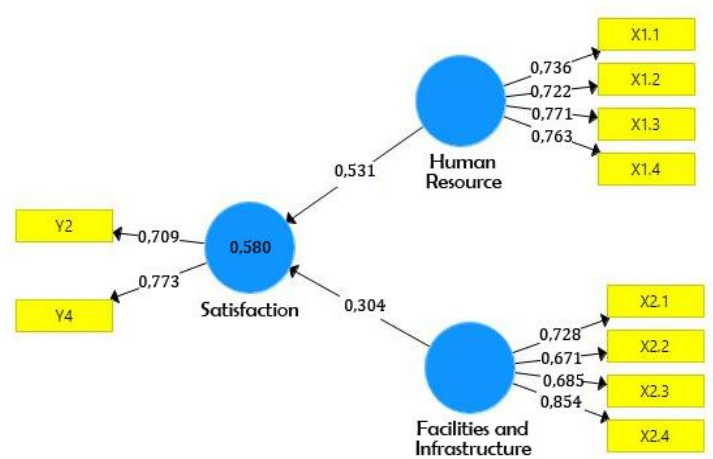

Figure 3. Outer Model (Final Indicators).

\section{Composite reliability}

A construct is said to have a high reliability when $\rho c>0,8$ and quite reliable if $\rho c>0,6$. The result of reability test with the reability of the relationship are as follows:

Table 5. Measurement of Composite Reliability Criteria.

\begin{tabular}{ll}
\hline Variable & Composite Reliability \\
\hline Satisfaction & 0,709 \\
Human Resource & 0,836 \\
Facilities and infrastructure & 0,826
\end{tabular}

Measurement results of composite reliability criteria, note that the variable of Human resource and variable of facilities and infrastructure has a value of reliability of the relationship between over 0,8 , which mean the variables have a fairly high reliability. Whereas, for the satisfaction variable has a value of the reliability of the relationship more than 0,6 what mean the the variable is quite reliable. It can be concluded that the all three variables are suitable and feasible and feasible to be used as variables to be tested to determined their effect on the dependent latent variable.
4. Cronbach's alpha

To test the consistency of each question, a cronbach's alpha measurement was performed. Cronbach's alpha said to be good if it has value $\geq 0,5$ and is said to be sufficient if it has value $\geq 0,3$. The results of the measurement of cronbach's alpha criteria are as follows:

Table 6 Measurement of Cronbach's Alpha Criteria.

\begin{tabular}{lc}
\hline \multicolumn{1}{c}{ Variable } & Cronbach 's Alpha \\
\hline Satisfaction & 0,183 \\
Human Resource & 0,742 \\
Facilities and & 0,728 \\
infrastructure & \\
\hline
\end{tabular}

From the result of the measurement above, both variabel latent independent have a cronbach alpha value $\geq 0,5$, which mean the variable can be said to be consistent. Meanwhile, the satisfaction variable has an cronbach's alpha value $<0,3$ which mean that there are a question in the satisfaction variable that are less consistent as a data measurement tool.

\section{- Inner Model}

Goodness of fit models are measured using $Q^{2}$ latent dependent variables with the same interpretation as regression. $Q^{2}$ the suitability of the predictions for the structural model, measuring how well the observational values generated by the model and also the estimated parameters. $Q^{2}>0$ values indicate that the model has a matched prediction. The opposite, if $Q^{2} \leq 0$ the value indicates the model lacks suitability predictions.

The result of measuring the inner model with PLS are as follows:

Table 7 Measurement of the Inner Model with.

\begin{tabular}{ccc}
\hline & $\boldsymbol{R}^{2}$ & Adjusted $^{2}$ \\
\hline $\mathrm{Y}$ & 0,580 & 0,556 \\
\hline
\end{tabular}

From the table $R^{2}$ above, the value of $R^{2}$ is 0,580 , so that the value $Q^{2}=1-(1-0,580)=0,580$ means $Q^{2}=R^{2}$. This result $R^{2}$ figure can be explained that the human resource variable $\left(\mathrm{X}_{1}\right)$ and facilities and infrastructure $\left(\mathrm{X}_{2}\right)$ give a value 0,580 as large as can be interpreted that the dependent latent variable can be explained by the independent latent variable of $58 \%$. While $42 \%$ explained by other variables outside the research. From these figures, it can be categorized that the dependent variable can be explained by independent variables on a moderate scale.

The $R^{2}$ adjusted value has a value with an interval between 0 and 1 . If the $R^{2}$ adjusted value is getting closer to 1 , then it shows that the independent latent variable $(\mathrm{X})$ explains the variation of the dependent 
latent variable (Y) better. In this study, it can be a value $R^{2}$ that is adjusted by 0,556 or $55.6 \%$. Then we can draw a conclusion that $55.6 \%$ of the variation that occurs in the variable $\mathrm{Y}$ can be explained by the independent latent variables, while the rest can be explained by the other variables.

\section{Hypothesis test}

In testing hypothesis, which analyzed the value is the value that existed at the t-statistic expected in silkan of output PLS which is then compared with the value of the t-table. Hypothesis testing with PLS is done by bootstrapping resampling method. The output is the result of bootstrapping PLS to test the hypothesis of the research is as follows:

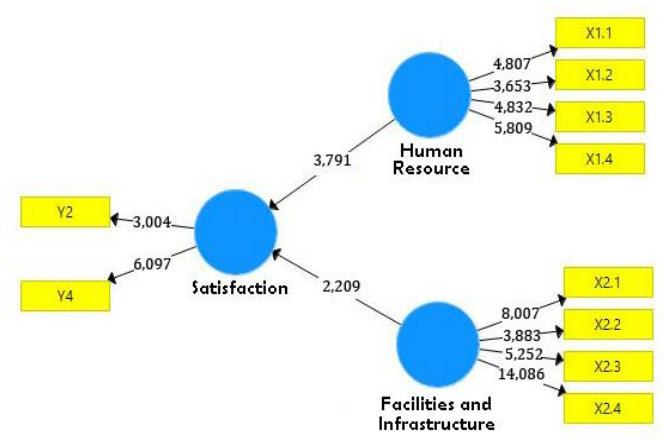

Figure 4. Bootstrapping PLS

1. Hypothesis 1: Effect of Human Resource on Satisfaction

Table 8. Bootstrapping Hypothesis 1.

\begin{tabular}{ccccc}
\hline & $\begin{array}{c}\text { Original } \\
\text { Sampel (O) }\end{array}$ & $\begin{array}{c}\text { Mean } \\
\text { Sample } \\
(\mathbf{M})\end{array}$ & $\begin{array}{c}\text { P- } \\
\text { value }\end{array}$ & $\begin{array}{c}\text { T Statistic } \\
(|\mathbf{O} / \mathbf{S T D E V}|)\end{array}$ \\
\hline $\boldsymbol{X}_{1} \rightarrow \boldsymbol{Y}$ & 0,531 & 0,553 & 0,000 & 3,910 \\
\hline
\end{tabular}

Hypothesis 1 which examined the relationship between Human Resource to satisfaction shows the value of the original sample of 0,531 and $t$-statistics 3,910 . The measurement result show that the t-statistic > t-table (level of significance $5 \%=0,68177$ ), then the first hypothesis in this study was accepted. From the results of these data, it can be interpreted that the sample data of the independent sample data of the independent latent variable (Human Resource) succeeded in proving the relationship with the dependent latent variable (Satisfaction), or in other words $X_{1}$ gives a significant influence on $\mathrm{Y}$ with the direction of a positive relationship.

2. Hypothesis 2: Effect of Facilities and Infrastructure on Satisfaction

Hypothesis 2 which examined the relationship between Human Resource to satisfaction shows the value of the original sample of 0,304 and t-statistics 2,230. The measurement result show that the $t$-statistic $>t$-table (level of significance $5 \%=0.68177$ ), then the second hypothesis in this study was accepted. From the results of these data, it can be interpreted that the sample data of the independent sample data of the independent latent variable (Facilities and Infrastructure) succeeded in proving the relationship with the dependent latent variable (Satisfaction), or in other words $\mathrm{X}_{2}$ gives a significant influence on $\mathrm{Y}$ with the direction of a positive relationship

Table 9. Bootstrapping Hypothesis 2.

\begin{tabular}{ccccc}
\hline & $\begin{array}{c}\text { Original } \\
\text { Sampel } \\
(\mathbf{O})\end{array}$ & $\begin{array}{c}\text { Mean } \\
\text { Sample } \\
(\mathbf{M})\end{array}$ & $\begin{array}{c}\text { P- } \\
\text { value }\end{array}$ & $\begin{array}{c}\text { T Statistic } \\
(\mid \mathbf{O} / \text { STDEV })\end{array}$ \\
\hline$X_{2} \rightarrow Y$ & 0,304 & 0,308 & 0,026 & 2,230 \\
\hline
\end{tabular}

\section{CONCLUSIONS}

In this study discussed the measurement of the practical satisfaction index of facilities and infrastructure as well as the performance of human resources in the basic chemical laboratory of the Faculty of Mathematics and Natural Sciences (MIPA) Jenderal Soedirman State University. Based on the results and discussion, the following conclusions can be obtained:

1. The satisfaction index measurement can be done with the Partial Least Square (PLS) approach, by evaluating a structural equation model of practitioner's satisfaction and analyzing the relationship between latent variables and indicators;

2. From the results of testing the effect of the human resource variable and the facilities and infrastructure variables on the satisfaction variable, it is known that the two variables namely the human resource variable and the facilities and infrastructure variable give a significant influence on the satisfaction variable with the direction of a positive relationship. This can be seen from the measurement results which show that the t-statistic value $>\mathrm{t}$ table (level of significance 5\% $=0.68177)$, that is, 3,910 for the t-statistic value of human resource variables for satisfaction and 2,230 for the t-statistic variable for facilities and infrastructure for satisfaction.

3. With approach Partial Least Square (PLS) to the satisfaction of the practice of an obtained model of the equation as follows:

Satisfaction $=0,531$ Human resource $+0,304$ Facilities and infrastructure

- There is influence between the variables human resource (with influential indicators) against to settle early for 0,531 meaning variables can affect the performance of human resources for the practitioner satisfaction percentage $53,3 \%$. 
- There is influence between the variables of facilities and infrastructure (with indicator indikator influential) against to settle early for 0,304 meaning variables can affect the performance of human resources for the practitioner satisfaction percentage $30,4 \%$.

\section{ACKNOWLEDGEMENTS}

This research was supported by [Jenderal Soedirman University]. We thank our college from [Faculty of Math and Science] who provided insight and expertise that greatly assisted the research, although they may not agree with all of the interpretations/ conclusions of this paper. We thanks to [Jenderal Soedirman University's college student] and [Sri Maryani, M.Si., Ph.D, Lecturer, Jenderal Soedirman University's] for comments that greatly improved the manuscript.

\section{REFERENCES}

Adam, Khaeryna, Irwan. 2015. Methods of Partial Least Square (PLS) and its Application (Case Study: Customer Satisfaction Analysis of Service Unit Camming PDAM Kab. Bone). Journal Teknosains 9 (1): 53-68.

Asra, Abuzar, Rudiansyah. 2017. Applied Statistics for Policy Makers and Decision Making. IN MEDIA, Bogor.
Bimo S. 2018. Construct Reliability and Variance Extracted Test on Structural Equation Modeling. http://www.statistikolahdata.com/

Ghozali I. 2008. Structural Equation Modeling Alternative Methods with Partial Least Square, second edition. [Thesis]. Diponegoro University, Semarang. [Indonesian]

Otok BW and Hidayat N. 2012. Modeling Structural Equation Modeling (SEM) based Varian's on Health Status in the Province of East Java in 2010. Paper presented at the National Seminar on Research, Education and Application of Mathematics and Natural Sciences, Faculty of Mathematics and Natural Sciences, Yogyakarta State University, 2 June 2012. [Indonesian]

Rifai A. 2015. Partial Least Square-Structural Equation Modeling (PLS-SEM) to Measure the Expectations of Using Institutional Repositories (Pilot Study at UIN Syarif Hidayatullah Jakarta). Al-Maktabah 14: 56-65.

Rodliyah M. 2016. Estimated Score Factor with Partial Least Square (PLS) in the Measurement Model (Case Study: Remuneration of Educational Personnel in the ITS Environment). [Unpublished Thesis]. ITS Surabaya, Surabaya. [Indonesian]

Sholiha EUN and Salamah M. 2015. Structural Equation Modeling-Partial Least Square for Modeling District/City Health Degrees in East Java (Case Study of East Java Community Health Development Index Data 2013). Journal of Science and its Art 4 (2): 169-174.

Sugiyono. 2013. Quantitative, Qualitative and Combination Research Methods. Alfabeta, Bandung.

Supangat A. 2007. Statistics in Descriptive, Inference and Nonparametric Studies. Kencana, Jakarta. 
THIS PAGE INTENTIONALLY LEFT BLANK 